\title{
Struktur data pemrograman
}

\author{
Rama dewantoro \\ 195120040 \\ Fakultas Komputer \\ Ramadewantoro.student@umitra.ac.id
}

\begin{abstract}
Programdisebutdengan kumpulan intruksi dan perintah yang disusun rapih sehingga memiliki urutan logika yang tepat untuk menyelesaikan suatu persoalan. Dan aplikasi yang digunakan adalah Turbo Pascal

Dan dapat dimaknai sebagai algoritma ditambah bahasa atau struktur data. Sebuah program yang baik, memiliki struktur data yang baikSebaliknya, struktur data yang buruk dengan algoritma yang baik tetap tidak akan membuat sebuah program menjadi baik.

Struktur Data disebutdengan tata letak Data yang berisi kolom-kolom data,baik itu kolom yang tampak oleh pengguna (user) ataupunkolom yang hanya digunakan untuk keperluan pemrograman yang tidak tampak oleh pengguna.

Algoritma yaitu susunan logisatausistematis untuk memecahkan suatu masalah atau untuk mencapai tujuan tertentu. Dalam dunia komputer, Algoritma sangat berperan penting dalam pembangunan suatu software.MungkintanpakitasadariAlgoritma juga termasukdalamkehidupankitaseharihari.
\end{abstract}

- KarakterAlgoritma

1. Input

2. Output

3. Definite ( jelas)

4. Efektive

5. Terminate ( Berakhir)

- Langkah - langkah Pembuatan Program

1. Mendefinisikan permasalahan

2. Membuat rumusan untuk memecahkan masalah

Dapat disusun dalam bentuk pseudocode maupun flowchart

Example : Pseudocode

Mulai

Input ( Bilangan 1)

Input ( Bilangan 2)

Hasil = Bilangan 1 + Bialanan 2

Output ( Hasil )

Selesai 
Example : Flowchart

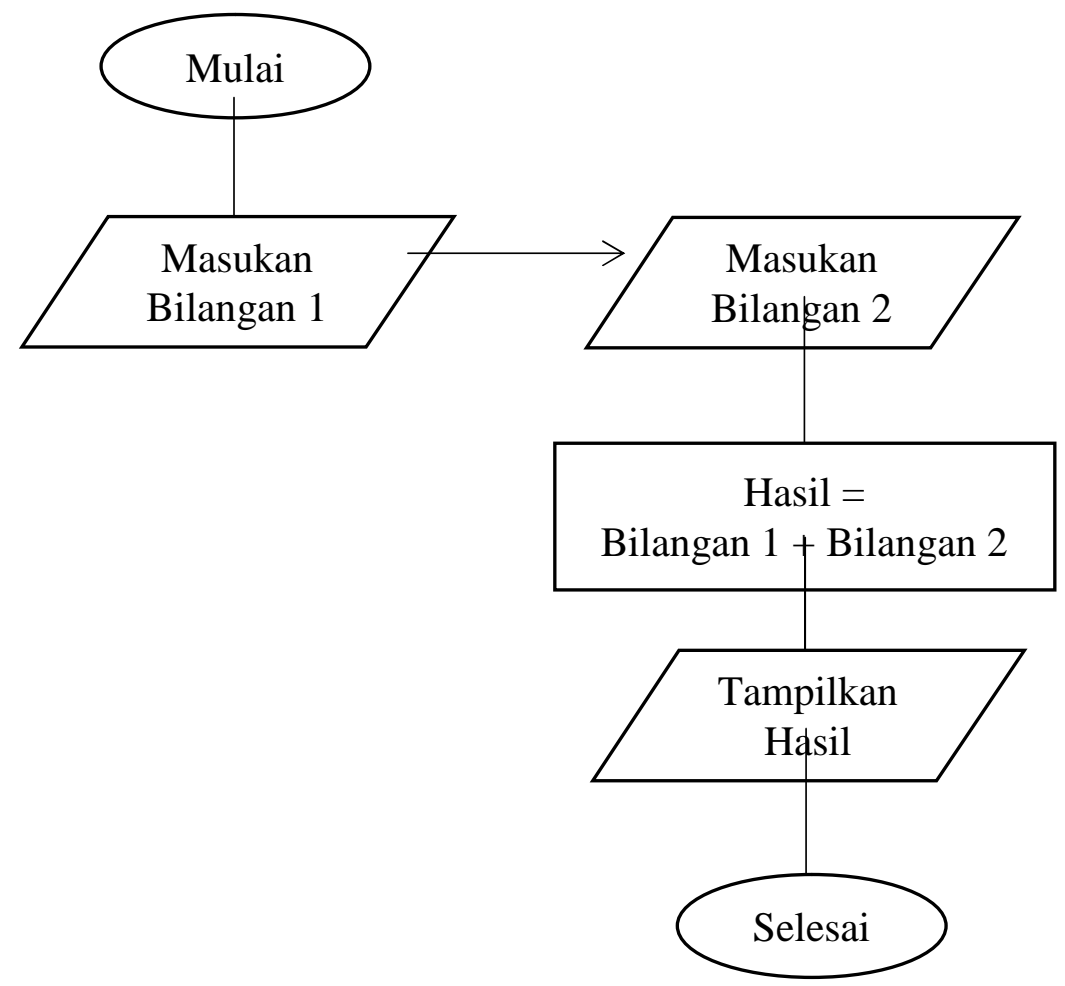


A. PENDAHULUAN

MembahastentangStruktur

Data mengenaiStruktur Data

Bahasa Program Turbo Pascal

,Algoritma danStruktur Data

KarakteristikAlgoritma.

Langkah -

langkahpembuatanprogramdanj

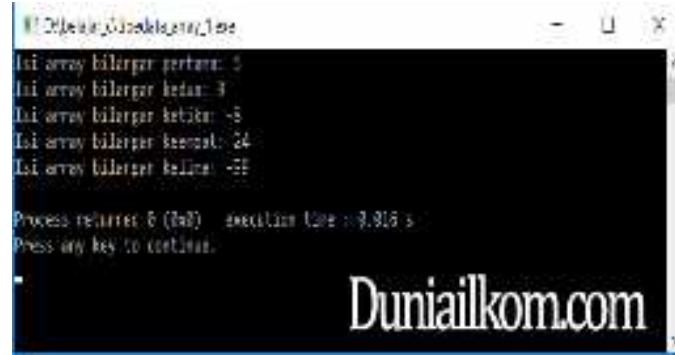

enis - jenisTipe Data .

- Jenis - jenis Type Data :

1. Type Sederhana ( simple type)

a. type ordinal

(untuksemuabilanganke

cualibilangan real)

@ integer [-32768 ...

32767] 2 bytes

@ shortint [-128 .. 127]

1 bytes

@ longint [-2147483648

.. 2147483647] 4 bytes

@ boolean [benar

..salah] 1 bytes

@ char [u karakter 1

huruf ] 'A' 1 byte (

ASCII )

@byte [ 0 .. 255 ] 1

byte

b. type real

(untukbilanganDesimal)

6 bytes

2. Type string (data yang berisisederetankarakter)

' INFORMASI'

3. Type terstruktur (structured type)

\section{untukukurantempat}

a. Larik ( Array )

memilikihasil data

dalamjumlahtetapnamu

ndengan type sama ,

contoh : [ 1..100]

b. Rekaman ( record ) serupadengan array, tapirekamantidakharuss erupadengan type data yang sama

c. Himpunan ( set) kumpulanobjek yang mempunyai type data yang sama

d. Berkas( file ) sejumlahkumpulankom ponen yang bertipe data yang sama.

4. Type pointer (

dijelaskandalambab SENARAI BERANTAI)

5. Tipe data Karakter (character/char) Jenis tipe data ini hanya memungkinkan sebuah variabel menyimpan informasi sebuah single karakter, seperti huruf "P", “c”, “7”, atau “@”.

\section{Contoh Type ARRAY :}

Sebagai contoh pertama, saya ingin membuat array bilangan dengan 5 element bertipe data integer, lalu mengisi dan menampilkan nilainya menggunakan perintah printf: 


\section{Contoh Type RECORD :}

TYPE rec_mhs = record

Nim : string (10);

Nama : string (20);

Jur : string (15)

End ;

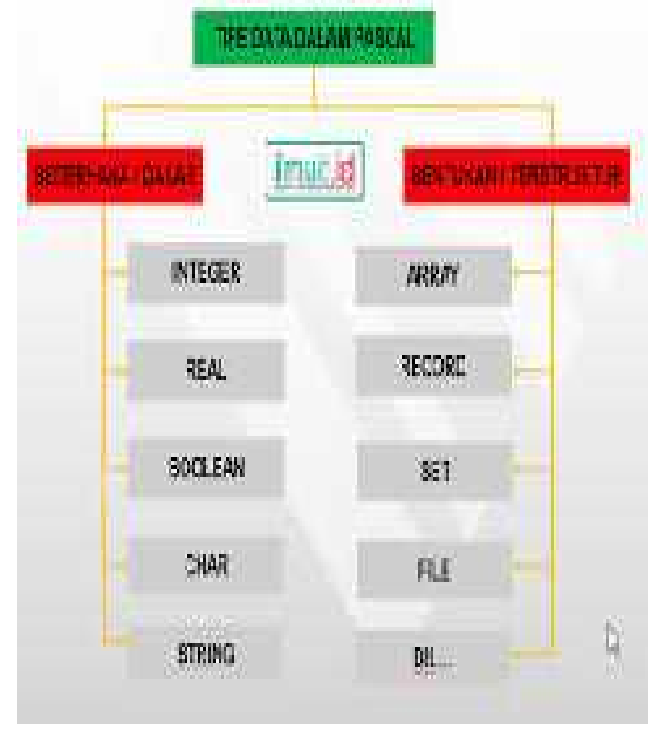




\section{B. PEMBAHASAN/STUDI KASUS}

Materi 1

membahastentangProgramyaitusekumpulan intruksiatau perintah dapattersusunrapihhingga memiliki urutan logika yang tepat untuk menyelesaikan suatu persoalan

Materi 2 membahastentangStruktur Data yaituuntukmengorganisasikan Data sedemikianrupasehinggapenerapanprogram menjadilebihterstruktur Materi 3 membahastentangAlgoritma yaitu susunan logisdansistematis agar dapatmemecahkansatumasalah agar mencapaitujuantertentu Materi 4 membahaskarakterAlgoritma yang terdiridari : Input, Output, Definite ( Jelas ) , Efective, Terminate ( Berakhir ) Materi 5 membahastentangLangkah langkahPembuatanAlgoritma sertacontoh Flowchart

C. ID SECURITY

QWTD4452377-ASP-5244166

\section{KESIMPULAN}

KesimpulandarimateriiniadalahStruk tur Data dapatmengorganisasikan Data sedemikianrupahinggapenerapanlebi hterstrukturdan lebih ringkas, danAlgoritma yang jelassehinggamenjadikanprogramkes eluruhan menjadi lebih mudah dan sederhana.

\section{E. DISKUSI}

Setelah saya berdiskusi dengan muhammad ardyansyah yhudy ,jika kita mengerti dasar apa yang di maksut struktur data, kita akan cepat memahami dan cepat mempelajari bagaimana fungsi struktur data yang sebenarnya, kurang lebih begitu.

\section{F. REFERENCE}

[1] O. M. Febriani and A. S. Putra, "Sistem Informasi Monitoring Inventori Barang Pada Balai Riset Standardisasi Industri Bandar Lampung," J. Inform., vol. 13, no. 1, pp. 90-98, 2014.

[2] A. S. Putra, "Paperplain: Execution Fundamental Create Application With Borland Delphi 7.0 University Of Mitra Indonesia," 2018.

[3] A. S. Putra, "2018 Artikel Struktur Data, Audit Dan Jaringan Komputer," 2018.

[4] A. S. Putra, "ALIAS MANAGER USED IN DATABASE DESKTOP STUDI CASE DB DEMOS."

[5] A. S. Putra, "COMPREHENSIVE SET OF PROFESSIONAL FOR DISTRIBUTE COMPUTING."

[6] A. S. Putra, "DATA ORIENTED RECOGNITION IN BORLAND DELPHI 7.0."

[7] A. S. Putra, "EMBARCADERO DELPHI XE 2 IN GPU-POWERED FIREMONKEY APPLICATION."

[8] A. S. Putra, "HAK ATAS KEKAYAAN INTELEKTUAL DALAM DUNIA TEKNOLOGY BERBASIS REVOLUSI INDUSTRI 4.0."

[9] A. S. Putra, "IMPLEMENTASI PERATURAN PERUNDANGAN UU. NO 31 TAHUN 2000 TENTANG DESAIN INDUSTRI BERBASIS INFORMATION TECHNOLOGY."

[10] A. S. Putra, "IMPLEMENTATION OF PARADOX DBASE."

[11] A. S. Putra, "IMPLEMENTATION OF TRADE SECRET CASE STUDY SAMSUNG MOBILE PHONE."

[12] A. S. Putra, "IMPLEMENTATION PATENT FOR APPLICATION WEB 
BASED CASE STUDI WWW. PUBLIKLAMPUNG. COM."

[13] A. S. Putra, "IMPLEMENTATION SYSTEM FIRST TO INVENT IN DIGITALLY INDUSTRY."

[14] A. S. Putra, "MANUAL REPORT \& INTEGRATED DEVELOPMENT ENVIRONMENT BORLAND DELPHI 7.0."

[15] A. S. Putra, "PATENT AS RELEVAN SUPPORT RESEARCH."

[16] A. S. Putra, "PATENT FOR RESEARCH STUDY CASE OF APPLE. Inc."

[17] A. S. Putra, "PATENT PROTECTION FOR APPLICATION INVENT."

[18] A. S. Putra, "QUICK REPORT IN PROPERTY PROGRAMMING."

[19] A. S. Putra, "REVIEW CIRCUIT LAYOUT COMPONENT REQUIREMENT ON ASUS NOTEBOOK."

[20] A. S. Putra, "REVIEW TRADEMARK PATENT FOR INDUSTRIAL TECHNOLOGY BASED 4.0."

[21] A. S. Putra, "TOOLBAR COMPONENT PALLETTE IN OBJECT ORIENTED PROGRAMMING."

[22] A. S. Putra, "WORKING DIRECTORY SET FOR PARADOX 7."

[23] A. S. Putra, "ZQUERY CONNECTION IMPLEMENTED PROGRAMMING STUDI CASE PT.
BANK BCA Tbk."

[24] A. S. Putra, D. R. Aryanti, and I. Hartati, "Metode SAW (Simple Additive Weighting) sebagai Sistem Pendukung Keputusan Guru Berprestasi (Studi Kasus: SMK Global Surya)," in Prosiding Seminar Nasional Darmajaya, 2018, vol. 1, no. 1, pp. 85-97.

[25] A. S. Putra and O. M. Febriani, "Knowledge Management Online Application in PDAM Lampung Province," in Prosiding International conference on Information Technology and Business (ICITB), 2018, pp. 181-187.

[26] A. S. Putra, O. M. Febriani, and B. Bachry, "Implementasi Genetic Fuzzy System Untuk Mengidentifikasi Hasil Curian Kendaraan Bermotor Di Polda Lampung," SIMADA (Jurnal Sist. Inf. dan Manaj. Basis Data), vol. 1, no. 1, pp. 21-30, 2018.

[27] A. S. Putra, H. Sukri, and K. Zuhri, "Sistem Monitoring Realtime Jaringan Irigasi Desa (JIDES) Dengan Konsep Jaringan Sensor Nirkabel," IJEIS (Indonesian J. Electron. Instrum. Syst., vol. 8, no. 2, pp. 221232.

[28] D. P. Sari, O. M. Febriani, and A. S. Putra, "Perancangan Sistem Informasi SDM Berprestasi pada SD Global Surya," in Prosiding Seminar Nasional Darmajaya, 2018, vol. 1, no. 1, pp. 289-294. 